\title{
Quantitative analysis of lecture-capture archive viewing by pharmacy students during the emergency switch to remote learning
}

\section{- Farhat Naz HUSSAIN ${ }^{1}$, Reem AL-MANNAI ${ }^{1}$, Abdelali AGOUNI ${ }^{1}$}

${ }^{1}$ College of Pharmacy, QU Health, Qatar University

\section{INTRODUCTION}

- Video lecture capture (VLC) is one of the most globally utilized e-tools by higher education institutions to support students' learning.

- At our institution, the rapid switch to remote learning was facilitated by the familiarity of faculty and students to various preexisting etools, particularly the Echo360 lecture capture system.

\section{AIM OF THE STUDY}

- To quantitatively analyze and evaluate whether the COVID-19 pandemic impacted the views of archived lecture recordings due to the emergency switch to distance-based learning in Spring 2020.

- To map the number of viewings of lecture archives to the time of the day, weeks of the term and the number of weekly assessments.

\section{METHODS}

1. Viewing data from September 2020 for 15 courses was compared to data previously extracted in November 2019.

2. The total number of views of Echo360 archives per week and per hour of the day in Spring 2019 was recorded and compared to Spring 2020.

3. Total views per week or day were also compared between pre- and post-suspension of in-person classes following the emergency switch to distance-based learning (before and after 9 March 2020).

\section{RESULTS and DISCUSSION}

Figure 1. Number of lecture archive views per week in Spring 2019 (A) and Spring 2020 (B)
A
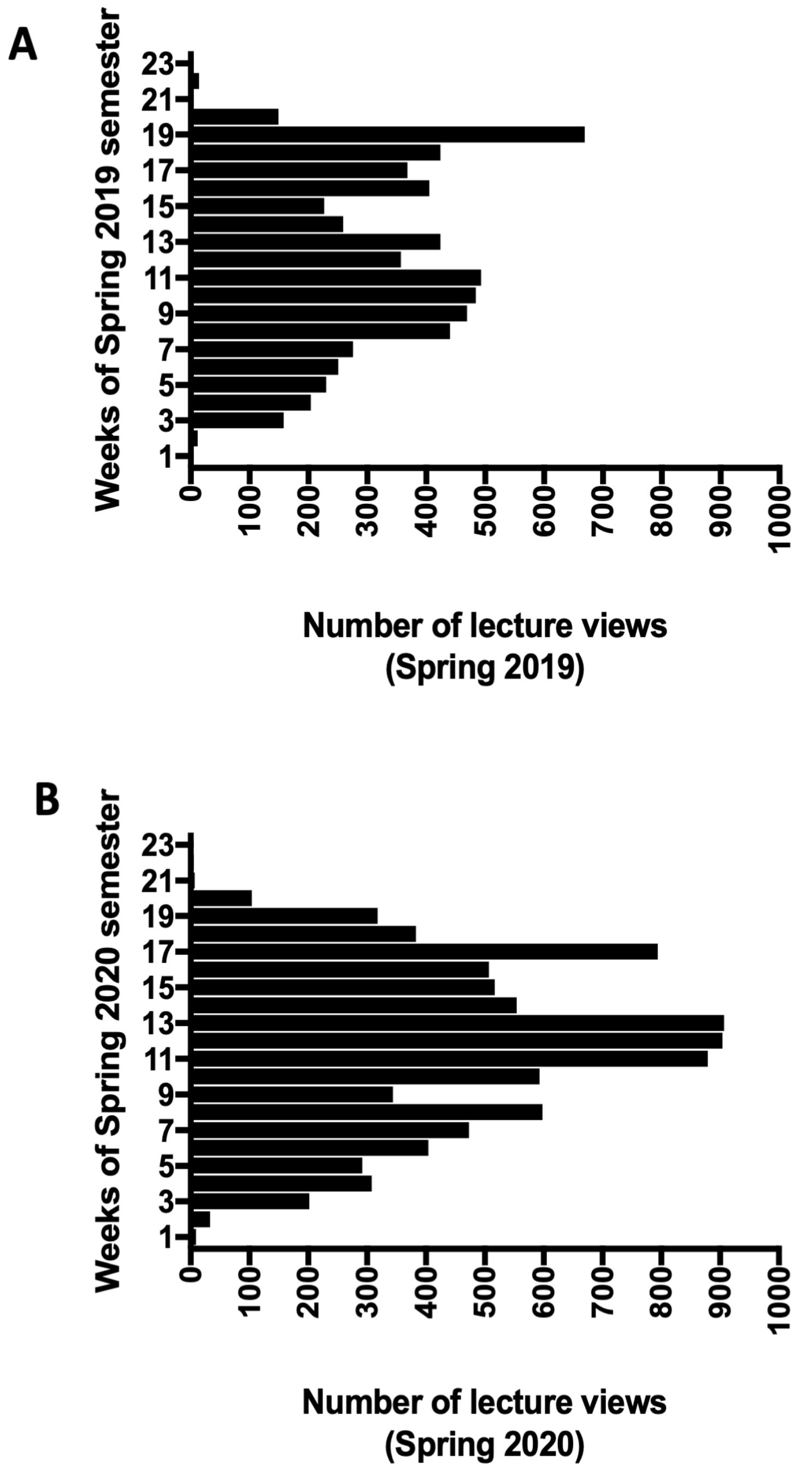
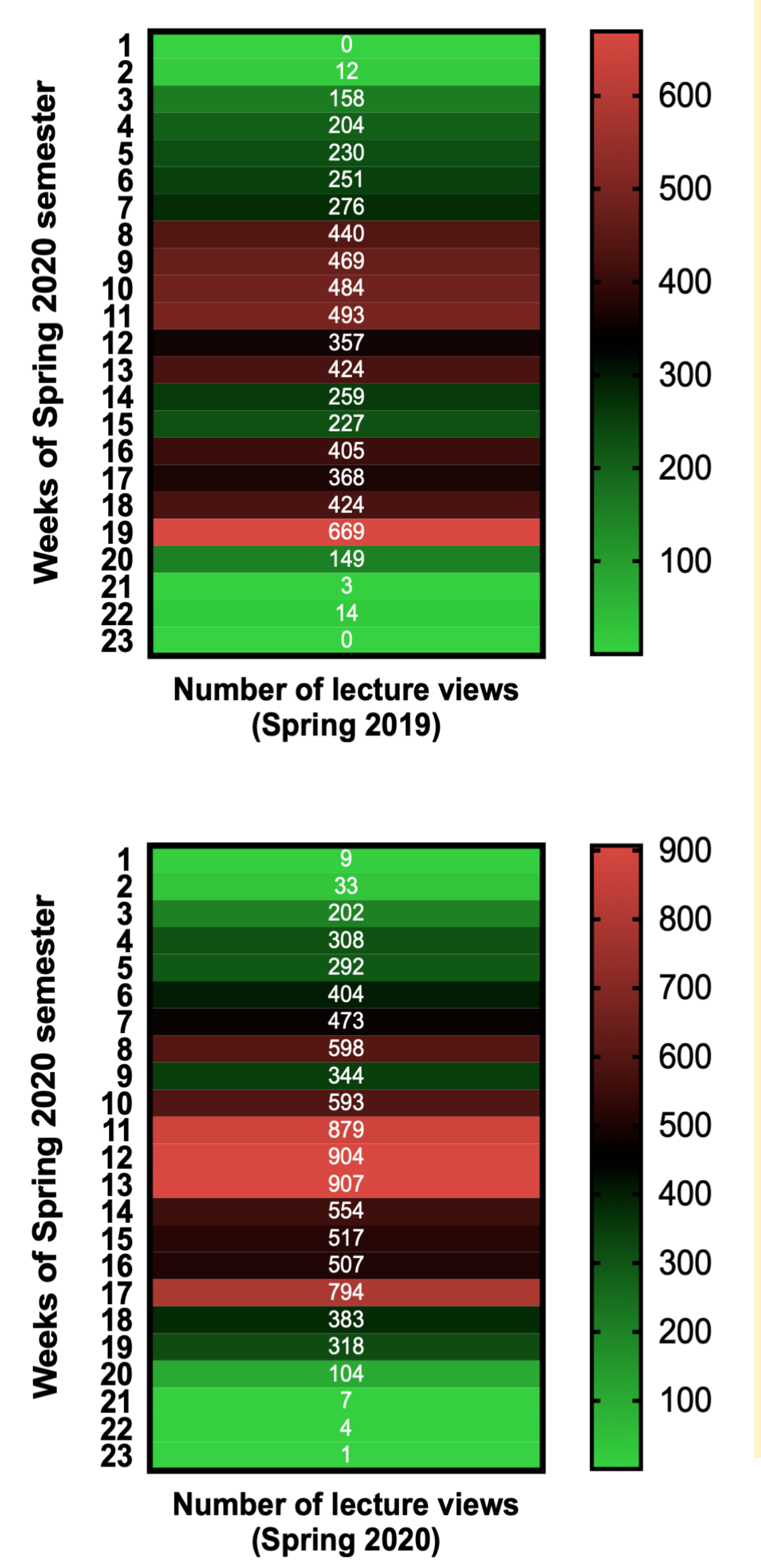

- Total number of Echo360 views in Spring $2020(9,135$ views) was $45 \%$ higher compared to Spring 2019 (6,316 views).

- Figure 1B shows the number of views increased sharply in weeks 11 (879 views), 12 (904 views) and 13 (907 views) of Spring 2020 which coincided with the beginning of in-person class suspension and the emergency switch to online learning.

Figure 2. Comparison of the average number of views per lecture for Spring 2019 lecture archives at two time points, November 2019 and September 2020. (E-I) views for P2 courses
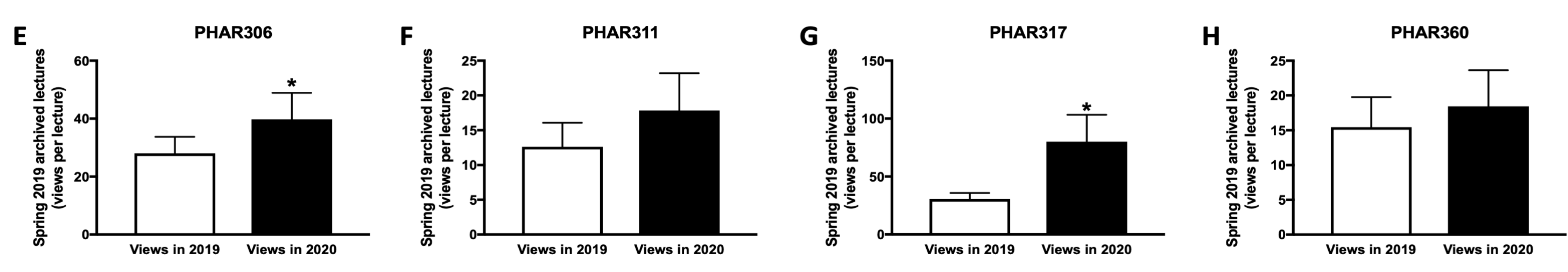

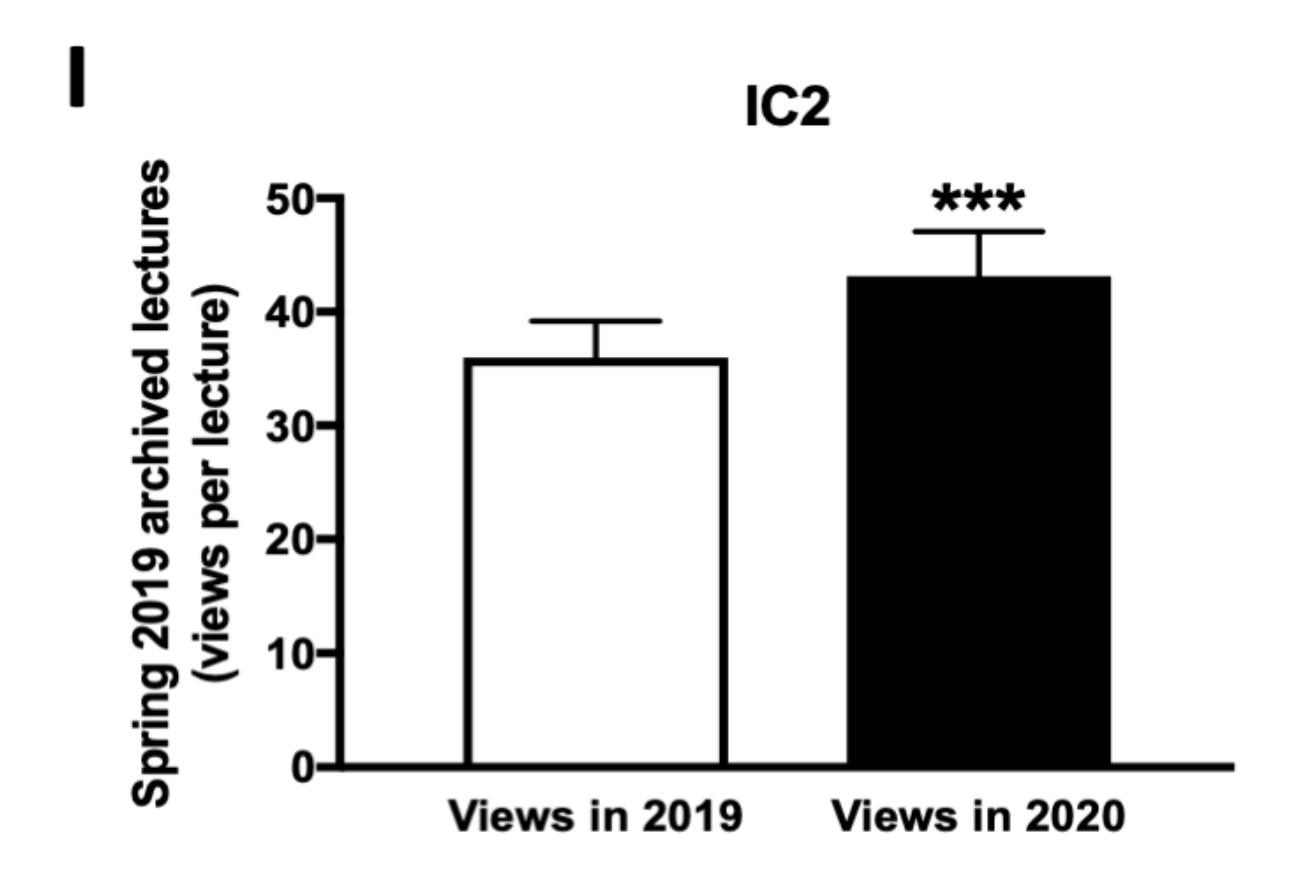

- Average number of views per lecture for Spring 2019 archives has increased for P1 courses and P2 courses (Figure 2E-2I) between November 2019 and September 2020.

- Most notably, PHAR317 course viewings increased by nearly 2.7-fold, from an average of 30 views per lecture in November 2019 to 80 views per lecture on September 2020 $(P<0.05)$ which amounts to more than one viewing on average for each student enrolled in the course in Spring 2020 (35 students were enrolled in Spring 2020).

\section{CONCLUSION AND FUTURE DIRECTIONS}

- The study provides evidence that lecture capture archives were heavily viewed by the students following in-person class suspension and during exam periods, which has supported the transition and rapid switch to online-based teaching.

- We highly recommend that higher education institutions adopt lecture capture, recording and archiving which reduced the negative impact of the on-campus suspension of educational activities and allowed invaluable time to both institution and instructors.

- Additional quantitative and qualitative studies must be conducted to fully grasp students' needs and driving force behind using Echo360 during the COVID-19 crisis. 